Lingua Rima: Jurnal Pendidikan Bahasa dan Sastra Indonesia

Vol. 10 No. 3 September 2021

http://jurnal.umt.ac.id/index.php/lgrm

\title{
DISKRIMINASI DAN SUPERIORITAS PEREMPUAN DALAM NASKAH DRAMA MEGA-MEGA KARYA ARIFIN C. NOER
}

\author{
Maya Fitrianingtyas ${ }^{1}$ \\ Universitas PGRI Madiun $^{1}$ \\ maya.fitrianingtyas08@gmail.com \\ Bambang Eko Hari Cahyono ${ }^{2}$ \\ Universitas PGRI Madiun ${ }^{2}$ \\ behc@unipma.ac.id \\ Dwi Rohmah Soleh ${ }^{3)}$ \\ Universitas PGRI Madiun $^{3}$ \\ dwirohman@unipma.ac.id
}

\begin{abstract}
ABSTRAK
Sastra dan tokoh perempuan adalah dua hal yang tak bisa dipisahkan. Perempuan menjadikan sastra menjadi lebih indah dan berwarna. Tokoh perempuan tersendiri menjadi sebuah pewangi di antara jalannya karya sastra yang beraneka, seperti pada hahlnya drama. Pada naskah drama Mega-mega karya Arifin C. Noer ini, aktivitas atau alur ceritanya menggambarkan banyak diskriminasi, selain itu tokoh perempuan menjadi sentral alur dan aktivitas semua adegan yang dilakukan dalam naskah dramanya. Tidak seperti nasib tokoh perempuan kebanyakan yang menderita di dalam karya sastra Indonesia yang lain, tokoh Mae dalam naskah drama ini mampu mendominasi aktivitas dan menjadi superior dalam kelompoknya, serta mendapat pengakuan dan posisi tersendiri. Tujuan penelitian ini berusaha mengungkapkan dan menjelaskan superioritas tokoh perempuan yang ada dalam naskah drama Mega-mega karya Arifin C. Noer. Penelitian ini menerapkan metode kualitatif deksriptif. Deskriptif kualitatif dalam penelitian menggunakan teknik analisis isi (content analysis) untuk mengkaji unsur superioritas tokoh perempuan yang terdapat pada naskah drama MegaMega karya Arifin C. Noer. Langkah analisis data yang dilaksanakan antara lain 1) penyajian, 2) reduksi, dan 3) pengambilan kesimpulan. Hasil dari analisis yang dilakukan pada penelitian ini antara lain: 1) diskriminasi dan superioritas perempuan dalam bidang sosial dan 2) kekuasaan atau penguasaan perempuan dalam hal ekonomi.
\end{abstract}

Kata kunci: Diskriminasi, Superioritas, Naskah Drama.

\section{A. PENDAHULUAN}

Karya sastra dan masyarakat merupakan dua hal berbeda namun tidak bisa dipisahkan. Realita kehidupan masyarakat merupakan alasan atau intisari dari terciptanya karya sastra. Sastra berkembang dan tumbuh pada aktivitas kebudayaan dan kemasyarakatan. Sebab itu, karya sastra tidak akan jauh dari pengungkapan permasalahan yang terjadi pada kehidupan sehari-hari bermasyarakat. Karya sastra adalah hasil dari proses penginderaan atau kreatif manusia yang didasari oleh ekspresi dari manusia sehingga menghasilkan karya baik dalam bentuk tulisan maupun lisan yang mempunyai nilai seni atau nilai estetik sebagai penggambaran tentang imaji dari kehidupan yang ada (Sumardjo \& Saini, 1986; Winarni, 


\section{Lingua Rima: Jurnal Pendidikan Bahasa dan Sastra Indonesia \\ Vol. 10 No. 3 September 2021 \\ http://jurnal.umt.ac.id/index.php/lgrm}

2009; Wellek \& Warren, 2016). Selain itu, karya sastra juga merupakan sebuah sarana bagi pengarang atau penulis untuk menuangkan isi perasaan dan pikiran terhadap sebuah fenomena yang terjadi pada pengetahuan serta kekuatan imaji dari pengarang (Widodo, 2020).

Sebuah karya sastra baik yang berbentuk prosa, puisi, ataupun drama pasti mempunyai latar belakang kebudayaan yang melekat baik dari penulis maupun hasil dari tulisannya. Pada naskah drama, penulis telah tahu betul dalam memasukkan unsur-unsur kehidupan yang telah ia renungkan sebelumnya. Unsur dalam kehidupan tersebut mempengaruhi kualitas dari hasil karya sastra yang tercipta. Dari berbagai unsur kehidupan yang telah termuat dalam karya sastra, salah satunya adalah tentang perempuan, atau yang biasa disebut dengan feminisme. Feminisme berakar dari kata awalnya femme, yang dalam bahasa Perancis mempunyai arti perempuan. Kemudain dari sini mulailah muncul gerakan kaum feminis yang secara khusus menyuarakan teori dan konsep yang berkaitan dengan kehidupan perempuan (Ratna, 2005). Lahirnya feminisme ini beralasan karena ketidakadilan yang menimpa kaum perempuan di berbagai lini kehidupan (politik, sosial, ekonomi). Kaitannya dengan karya sastra, feminisme muncul sebagai ranah baru pemaknaan isi dan penulisan yang dalam karya sastra tersebut membahas tentang pergolakan hidup baik batin maupun sosial yang terjadi pada kehidupan tokoh perempuan pada karya sastra tersebut.

Berdasarkan naskah drama, unsur feminisme sebetulnya tidak sebanyak dengan yang ditemukan pada prosa, baik cerpen maupun novel. Faktor yang mendasari ini karena disebabkan karena penulis perempuan yang bergerak pada gerakan feminisme lebih banyak melakukan pergerakan pada novel dan cerpen. Sedangkan pada drama, kebanyakan unsur yang diangkat adalah tentang sosial berupa kehidupan orang-orang yang terpinggirkan ataupun kritikan terhadap penguasa. Pemilihan naskah drama berjudul Mega-Mega karya Arifin C. Noer untuk dikaji dengan pendekatan feminisme sastra ini, dikarenakan naskah drama ini merupakan bentuk diskriminasi yang dilakukan dan juga penggambaran penguasaan dominasi atau superioritas yang dilakukan oleh seorang tokoh bernama Mae kepada tokoh lainnya, sehingga jalannya cerita pada drama ini menjadikan tokoh Mase menjadi tokoh sentral yang sangat berpengaruh. Diskriminasi adalah upaya penerapan dari kelompok mayoritas yang mengintervensi dan menekan kelompok minoritas, agar dapat mendapatkan penerimaan atau pengakuan dalam sistem yang umum (Mustika, 2016). Tapi berbeda dengan tokoh perempuan yang selalu menderita dan mengalami pergolakan dalam batin kehidupannya, tokoh Mae ini berhasil menjadi superior daripada tokoh-tokoh yang lainnya yag terdapat pada naskah drama Mega-Mega karya Arifin C. Noer ini. Adler (dalam 
Lingua Rima: Jurnal Pendidikan Bahasa dan Sastra Indonesia

Vol. 10 No. 3 September 2021

http://jurnal.umt.ac.id/index.php/lgrm

Fudyartanta, 2012: 15) mengemukakan, bahwasanya superioritas bukanlah merupakan pengotakan secara sosial, posisi-posisi dalam kepemimpinan, atau tinggi rendahnya suatu derajat dalam kehidupan bermasyarakat. Superioritas adalah bentuk karakteristik yang mempunyai arah tujuan untuk memperbaiki kualitas dalam kehidupan guna bisa menjadi manusia yang unggul dan memiliki pengaruh terhadap sesamanya (superior).

Penelitian serupa yang membahas tentang naskah drama Mega-Mega karya Arifin C. Noer ini antara lain, peneltian yang dilakukan oleh Maulidiana (2020) dengan judul Konflik Batin Tokoh Mae dalam Naskah Drama Mega-Mega karya Arifin C. Noer. Penelitian ini membahas dan mendeskripsikan tentang konflik batin yang dialami oleh Tokoh Mae dengan menggunakan pisau bedah Psikologi sastra. Selain itu ada juga penelitian serupa yang dilakukan oleh Sayuti (2019) dengan judul Pemeran Tokoh Mae dalam Naskah Drama MegaMega karya Arifin C. Noer dengan Metode Akting Stanislavsky.Penelitian ini memjabarkan dan tindak menghadirkan pemeranan tokoh Mae bukan hanya dari fisik, juga memberikan penjelasan psikologi yang dialami tokoh Mae tersebut.

Dari dua kajian relevan yang membahasa tentang naskah drama tersebut, penelitian masuk ke dalam kategori penelitian terbaru karena membahas tentang unsur feminisme seperti diskriminasi dan juga superioritas yang terjadi dalam naskah drama Mega-Mega karya Arifin C. Noer. Maka dari itu, penelitian ini bertujuan untuk menjabarkan atau mendeskripsikan tentang bentuk diskriminasi dan superioritas tokoh perempuan dalam bidang ekonomi, kehidupan sosial, dan juga seksualitas yang terdapat pada naskah drama Mega-Mega karya Arifin C. Noer.

\section{B. METODE PENELITIAN}

Penelitian ini menerapka metode kualitatif deksriptif. Deskriptif kualitatif dalam penelitian menggunakan teknik analisis isi (content analysis) untuk mengkaji unsur superioritas tokoh perempuan yang terdapat pada naskah drama Mega-Mega karya Arifin C. Noer. Metode ini diterapkan guna memecahkan masalah atau menjawab permasalahan yang tersaji secara kompleks atau yang aktual dengan cara mengumpulkan, menyusun, mengklarifikasi, menganalisis, dan menginterpretasi (Ratna, 2007). Deskriptif merupakan metode atau jenis penelitian yang dilakukan berdasarkan fakta dan fenomena yang dilakukan dengan pengamatan pada sumber datanya, sehingga menghasilkan catatan berupa kata-kata atau narasi yang bersifat memaparkan (Sugiyono, 2011). Objek penelitian pada penelitian ini 
Lingua Rima: Jurnal Pendidikan Bahasa dan Sastra Indonesia

Vol. 10 No. 3 September 2021

http://jurnal.umt.ac.id/index.php/lgrm

yaitu naskah drama berjudul Mega-Mega karya Arifin C. Noer. Teknik pengumpulan data yang dilaksanakan oleh peneliti yaitu dengan melakukan studi pustaka untuk mencari dan mengumpulkan bahan dan informasi dari kepustakaan yang berkaitan dengan objek yang diteliti (Faruk, 2012). Selanjutnya yang dilakukan oleh peneliti yaitu teknik simak, kegiatan pengumpulan data dari hasil simakkan catatan yang sekait dengan data penelitian. Kemudian yang terakhir yaitu teknik catat, guna menyimpulkan hasil pustaka dan menyimak dari objek yang diteliti. Proses analisis yang diterapkan pada penelitian ini yaitu dengan tiga tahapan: (1) mengumpulkan data, (2) mereduksi data, dan (3) menyajikan data. Pengumpulan data dilakukan dengan mencari atau menggali kalimat atau dialog yang mengaandung unsur superioritas tokoh perempuan yang nantiya akan menjadi data atau objek dalam penelitian ini. Langkah selanjutnya yang akan dilakukan yaitu reduksi data. Data yang selanjutnya menjadi akan direduksi sesuai kelompok sesuai dengan klasifikasi atau jenis dari klasifikasi data yang sudah ditentukan. Setelah data terkumpul dan direduksi, maka data akan analisis sehingga menghasilkan sebuah gambaran atau pemaknaan tentang diskriminasi dan superioritas perempuan yang termuat pada naskah drama Mega-Mega karya Arifin C. Noer.

\section{HASIL PENELITIAN DAN PEMBAHASAN}

Hasil yang didapatkan daalam anlisis data yang dilakukan terhadap naskah drama Mega-Mega karya Arifin C. Noer ini antara lain; 1) diskriminasi dan superioritas tokoh perempuan terhadap kehidupan ekonomi, serta 2) diskriminasi dan superioritas tokoh perempuan terhadap kehidupan sosial.

\section{Diskriminasi dan Superioritas Tokoh Perempuan terhadap Kehidupan Ekonomi}

Tokoh perempuan dalam naskah drama Mega-Mega karya Arifin C. Noer merupakan sosok sentral dalam drama ini, bahkan diakui atau tidak sosok tokoh perempuan seperti Mae seolah menjadi ibu bagi tokoh-tokoh lainnya. Karena itulah, dapat dikatakan tokohtokoh dalam drama Mega-Mega karya Arifin C. Noer ini menjadi sebuah keluarga walaupun berasal dari latar belakang yang berbeda, namun sama-sama menjadi orang yang terpinggirkan.

Pada rumah tangga, perempuan mempunyai peran atau posisi sebagai ibu yang bisa memanajemen serta melaksanakan pekerjaan domestik. Hal tersebut terjadi sebagai penunjang dan pengakomodir kebutuhan keluarga agar bisa tercukup (Aswiyati, 2016). Perempuan mempunyai kuasa ekonomi atas laki-laki karena mempunyai keterampilan 
Lingua Rima: Jurnal Pendidikan Bahasa dan Sastra Indonesia

Vol. 10 No. 3 September 2021

http://jurnal.umt.ac.id/index.php/lgrm

dalam memanajemenkan keuangan atau mengatur perekonomian seperti yang di gambarkan pada dialog dalam naskah drama Mega-Mega karya Arifin C Noer di bawah ini.

HAMUNG : Tidak usah. Saya anggap saja jumlahnya terlampau banyak sehingga sukar dihitung oleh tiga orang.

MAE : (mengancam) jangan berani kau merampasnya, Hamung. Jangan sekali-kali kau ambil uangnya. Uang itu hak miliknya.

HAMUNG : Siapa yang akan merampas uangmu, Nut?

PANUT : Tidak ada. Malah saya ingin memberikan kepada Mas Hamung sedikit.

MAE : Jangan. kau anak tolol. Uang itu uangmu sendiri. Kenapa kau berikan kepada orang lain?

PANUT : Tidak semuanya.

MAE : Jangan.

PANUT : Mae nanti juga saya beri.

MAE : Jangan.

PANUT : Ini uang saya. Uang saya sendiri.

MAE : Tapi kau anak saya.

PANUT : Tapi kau bukan ibu saya.

(Hamung tersenyum. Lama diam mereka)

(Noer, 1999).

Tokoh Mae yang digambarkan sebagai seorang ibu dalam keluarga gelandangan itu pun mengambil peran sebagai mestinya seorang ibu mengatur atau mengelola keuangan anak-anaknya.

Mae dalam naskah drama tersebut menjadi sosok ibu yang menjadi pengatur dan menguasi aspek ekonomi dari tokoh Panut dan Hamung dalam mengelola perekonomiannya lewat mengatur pembagian uang yang didapati oleh Panut. Langkah yang diambil Mae ini menjadi penggambaran dari diskriminasinya terhadap Hamung dan superioritasnya terdapat Panut dalam mengelola keuagannya.

Perempuan pastinya memiliki kemampuan atau keterampilan lebih dalam hal memanajemen keuangan dengan caranya masing-maisng, karena merekalah yang mengetahui seluk-beluk tentang keuangan keluarganya. Mae sebagai penggambaran perempuan dalam hal ini terkesan atau terhambarkan mempunyai kekuasaan untuk mengelola keuangan, seperti yang termuat dalam naskah drama.

\section{Diskriminasi dan Superioritas Tokoh Perempuan terhadap Kehidupan Sosial}

Kehidupan sosial yang berlangsung pada naskah drama ini menceritakan tentang kehidupan orang-orang pinggiran yang melaksanakan hari-harinya dengan pekerjaannya 


\section{Lingua Rima: Jurnal Pendidikan Bahasa dan Sastra Indonesia}

Vol. 10 No. 3 September 2021

http://jurnal.umt.ac.id/index.php/lgrm

yang dipandang sebeleha mata oleh masyarakat. Diskriminasi dan superioritas ini terdapat dalam kutipan-kutipan yang terjadi pada dialog dalam naskah drama Mega-Mega karya Arifin C. Noer seperti di bawah ini.

MAE : Nah, itu baik sekali. Mae percaya kau memang anak yang baik. Kau pernah dengar suara adzan tidak?

PANUT : Setiap kali saya dengar.

MAE : Maksudku kau percaya pada Tuhan tidak?

PANUT : Seperti setiap orang. Tapi Mas Woto bilang Tuhan itu tidak ada. Tuhan itu racun. Tuhan itu arak. Candu. Tuhan itu asap rokok. Kata Mas Marwoto.

MAE : Itu tidak perlu. Kau sendiri percaya tidak? kalau kau percaya memang tak layak kau mencopeti barang milik orang lain.

PANUT : Saya bilang saya tidak akan mencopet lagi. Bajingan. Kemarin saya coba-coba bantu Mas Wiryo tapi sial juga.

MAE : Membantu apa?

PANUT : Maling.

(Noer, 07:1999).

Kekuasaan yang diperlihatkan perempuan memang terlampau sedikit apabila dibandingkan dengan kekuasaan laki-laki. Pada perjuangannya, perempuan memikirkan sebuah konsep atau gagasan untuk menyatarakan atau setidaknya mensejajarkan keadilan atas hak-hak perempuan agar dapat berkuasa.

Budaya patriarki, menyebabkan posisi atau kedudukan perempuan menjadi di bawah dari posisi atau kedudukan dari laki-laki. Pekerjaan di ranah publik yang menjadi sorotan dan pengalaman di kalangan masyarakat umum menjadi sebuah hal yang tabu yang diterima oleh perempuan, daripada laki-laki. Keadilan gender ini menilmbulkan perjuangan untuk mencapai kesetaraan yang diperjuangan oleh kaum perempuan. Perjuangan tersebut meliputi hak-hak dalam berpolitik, mengemukakan pendapat, dan juga dalma pengambilan keputusan (Harun, 2015).

Pada Mega-Mega yang ditulis oleh Arifin C. Noer ini mengandung nilai-nilai yang kuat tentang superioritas yang berpengaruh terhadap kehidupan sosial. Tokoh Mae sebagai perempuan, mempunyai tingkat superioritas tinggi yang berkaitan dengan mengambil sebuah keputusan atas orang lain. Tokoh Mae memiliki mempunhyai posisi yang tinggi sebagai ibu pada lingkungan kumuh yang ditinggalinya dan tokoh-tokoh lainnya. Selain itu, ada pula contoh yang memiliki keterkaitan antara perempuan dan juga kepemimpinan di bawah ini.

MAE : Sabar.

HAMUNG : Susah, bukan ? Lebih baik tidak ambil pusing. 


\section{Lingua Rima: Jurnal Pendidikan Bahasa dan Sastra Indonesia}

Vol. 10 No. 3 September 2021

http://jurnal.umt.ac.id/index.php/lgrm

TUKIJAN : Mereka kira semua yang tidur di emper-emper adalah pencuri-pencuri.

MAE : Biarkan saja.

TUKIJAN : Mereka orang-orang beragama. Saya berani taruhan, sebagian besar dari mereka lebih jahat daripada penghuni emper-emper toko. Untung saja mereka punya pakaian yang bagus-bagus dan bersih-bersih.

HAMUNG : Kau sendiri diam-diam menyamaratakan mereka.

TUKIJAN : Tidak.

HAMUNG : Mudah-mudahan.

( Muncul Retno )

RETNO : Mae, kemana dia?

MAE : Siapa?

RETNO : Si banci tadi. Kemana dia? Saya melihatnya tadi dekat masjid.

MAE : Pemuda?

RETNO : Ya. Kemana?

MAE : Kemana ya? Mae kira kesana. Ke arah bioskop Sobo.

RETNO : Huh, patah lehernya nanti, saya cekik. Betul bukan? Sampai tujuh keliling si banci itu akan berputar-putar sekitar alun-alun ini membuntuti saya. Kemana tadi?

MAE : Ke Sobo. Tapi kenapa harus kesana? Lagipula sudah pagi.

RETNO : Ke Sobo? Saya peluk dia

(Noer, 100-101:1999).

Diskriminasi gender pada agama Islam ini dicontohnya sebagai hak kesaksian di ranah umum, poligami, dan juga hak warisan. Perempuan melalui pergerakannya berusaha sebagaimana mestinya agar dilakukan penyetaraan poisinya agar sejajar dengan laki-laki untuk menjadi seorang pemimpin. Usaha perempuan tersebut mempunyai banyak pertentangan sehingga memunculkan banyak kontroversi

Selain dari keterangan yang telah dibahas dan dianalisis kutipan dialog dari naskah drama Mega-Mega karya Arifin C. Noer, terdapat juga data atau kutipan yang menjealskan bahwa tokoh perempuan sebagai pusat dari sebuah keputusan, berikut kutipannya.

RETNO : "Sejak gadis dulu aku mengidamkan dapat melahirkan anak laki-laki. Anak itu lakilaki dengan mata yang teduh seperti kolam. Hatiku selalu bergetaran menyanyi setiap kali bertemu dengan mata itu. Tapi makin lama mata itu makin kering sebab bapaknya tidak pernah melakukan apa-apa. Suatu ketika aku sakit. (lama diam) Anak itu sakit. Kelaparan. Ia mati. Sejak itu aku hampir gila oleh perasaan kecewa dan kesal. (diam) Suatu hari suamiku pulang setelah menuntaskan bergelas-gelas arak. Bukan main aku marah. Dan sekonyong nasib turut campur. Rumah itu terbakar (gerahamnya merapat ketat) Setan! Setan!"

MAE : "Pendeknya kalian berdua. Kalian berdua salah. Kalian malas. Kalau anak itu sekarang masih hidup, barangkali ia sudah cukup mampu menolong kau. Saya yakin kau sangat menyesal dan suatu ketika kau bisa gila bila kau merasa kangen kepada anak yang malang itu."

RETNO : "Sudahlah."

MAE : "Retno...."

(Noer, 16-17: 1999). 


\section{Lingua Rima: Jurnal Pendidikan Bahasa dan Sastra Indonesia}

Vol. 10 No. 3 September 2021

http://jurnal.umt.ac.id/index.php/lgrm

Retno pada kutipan di atas digambarkan sebagai perempuan yang mempunyai kekuasaan. Sebagai pelacur, Retno mempunyai emosional yang cukup tinggi. Sikap emosional yang dimiliki Retno ini merupakan penggambaran bahwa seorang perempuan ingin mempunyai kuasa dan kepemilikkan penuh terhadap sesuatu.

Tokoh Retno mempunyai keinginan atau impian untuk memiliki anak yang baik, lucu serta sempurna. Meskipun berperan sebagai pelacur, Retno pun mempunyai karakter keibuan yang tidak terhindarkan. Pada keinginannya mempunyai anak, Retno berusaha sebisa mungkin atau bahwa memaksa agar nasib baik memihak kepadanya. Penggambaran inilah yang membuat Retno mempunyai sifat yang menjelaskan bahwa perempuan dapat menjadi penentu dari sebuah keputusan. Selain pusat kepemimpinan dan pengambilan keputusan, perempuan juga dapat mempunyai superioritas sebagai sumber pengaruh. Perempuan sebagai sumber pengaruh ini digambarkan oleh kutipan berikut.

HAMUNG : Lucunya dia cuma ingin punya uang bertumpuk. Tapi sintingnya, sedikitnpun ia tidak mau bekerja. Ia cuma ngemis.

PANUT : Makan pun tak mau ia urunan seperti kita-kita ini. Dia cuma makan. Bayar tidak mau.

RETNO : (tertawa) Dan edannya uang hasil minta-minta nya ia belikan lotre. Entah sudah berapa puluh lembar lotre dibelinya. Satu kalipun belum pernah ia menang.

MAE : Biarkan ia tidak urunan. Ini permintaan Mae. Mae bilang, kalau kalian semua yang Mae masakkan boleh Mae anggap sebagai anak-anak Mae. Dan sudah umumnya anak-anak. Tidak semuanya rajin. Mesti ada saja yang nakal ataupun malas. Mae ingin kalian semua rukun satu sama lain. Sedikit-sedikit yang malas diajar kerja. Sedikit-sedikit yang suka nyopet diajar kerja. Mae ingin semua senang lahir batin.

(Noer, 23: 1999).

Perempuan mempunyai partisipasi yang kuat dan nilai yang kuat dalam pengambilan keputusan. Namun, saat pengambilan keputusan, kaum perempuan akan lebih kritis dan cenderung memikirkan hal yang mungkin dapat terjadi setelahnya. Respon ini pun mempunyai berbagai pandangan dari yang lainnya agar keputusan yang telah diambil oleh perempuan ini tidak mempunyai hal yang negatif. Pengaruh yang kuat dari perempuan ini, menjadi sebuah acuan dalam memutuskan sebuah keputusan. Seperti pada keputusan pada keluarga, menamejemen ekonomi, dan mengambil keputusan-keputusan yang lainnya pada keluarga dan juga lingkungan.

Pada kutipan naskah drama Mega-Mega karya Arifin C. Noer yang telah dianaisis di atas, data-data yang telah dipaparkan tersebut menggambarkan bahwa diskriminasi dan superiortas yang berorientasi pada posisi sentral perempuan ini diakibatkan oleh banyak hal. Kemiskinan 
Lingua Rima: Jurnal Pendidikan Bahasa dan Sastra Indonesia

Vol. 10 No. 3 September 2021

http://jurnal.umt.ac.id/index.php/lgrm

dan kepapaan dari setiap tokoh yang diceritakan pada naskah drama Mega-Mega karya Arifin C. Noer ini menjadi sisi atau latar belakang dari cerita yang mengalir dari setiap kutipan naskah drama tersebut.

Diskriminasi dan superioritas yang terjadi pada naskah drama Mega-Mega karya Arifin C. Noer ini lebih bayak didapati pada aspek kehidupan sosiakl ketimbang kehidupan ekonomi. pada kehidupan ekonomi, diskriminasi dan superioritas hanya ditemukan sedikit data atau kutipan yang menjelaskan tentang diskriminasi dan superioritas pada naskah drama MegaMega karya Arifin C. Noer. Sebaliknya, dalam aspek kehidupan sosial, diskriminasi dan superioritas ditemukan pada tiga aspek kehidupan sosial. Aspek-aspek tersebut terdiri dari: 1) perempuan sebagai penentu kepemimpinan, 2) perempuan sebagai pengambilan keputusan, dan 3) perempuan sebagai sumber yang memiliki pengaruh.

\section{SIMPULAN DAN SARAN}

Pada penelitian yang dilakukan pada naskah drama Mega-Mega karya Arifin C. Noer, ditemukan data-data dan fakta-fakta menarik tentang adanya unsur feminisme berupa diskriminasi dan juga superioritas yang justru sosok sentralnya adalah tokoh perempuan. Tidak seperti karya sastra feminis lain yang menempatkan tokoh perempuan sebagai sosok korban yang ditindas dan mendapatkan ketidakadilan, tokoh perempuan seperti Mae dan Retno yang ditemukan dalam naskah drama Mega-Mega karya Arifin C. Noer ini justru menjadi sentral dan posisi yang strategis yang menyebabkan adanya diskriminasi dan superioritas yang terjadi di antara tokoh yang lain. Diskriminasi dan superioritas itu terwujud dalam hasil analisis yang menyebutkan tentang diskriminasi dan superioritas perempuan dalam kehidupan ekonomi serta diskriminasi dan superioritas perempuan dalam kehidupan sosial yang mempunyai tiga (3) aspek berupa 1) perempuan sebagai penentu kepemimpinan, 2) perempuan sebagai pengambilan keputusan, dan 3) perempuan sebagai sumber yang memiliki pengaruh. Semoga dari dilakukannya penelitian ini, mendorong penelitian sejenis yang membahas tentang feminisme sastra ataupun juga penelitian yang membahas naskah drama Mega-Mega karya Arifin C. Noer.

\section{E. DAFTAR PUSTAKA}

Aswiyati, I. (2016). Peran Wanita dalam Menunjang Perekonomian Rumah Tangga Keluarga Petani Tradisional untuk Penanggulangan Kemiskinan di Desa Kuwil Kecamatan Kalawat. HOLISTIK, IX(17). 
Lingua Rima: Jurnal Pendidikan Bahasa dan Sastra Indonesia

Vol. 10 No. 3 September 2021

http://jurnal.umt.ac.id/index.php/lgrm

Fudyartanta, K. (2012). Psikologi Kepribadian Timur. Pustaka Pelajar.

Maulidiana, A. (2020). Konflik Batin Tokoh Mae dalam Drama Mega-mega Karya Arifin C. Noer (Kajian Psikologi Sastra). Universitas Muhammadiyah Malang.

Mustika. (2016). Diskriminasi Terhadap Beberapa Perempuan Dalam Perspektif Feminisme Multikutural: Kajian Terhadap Novel Scappa Per Amore Karya Dini Fitria. Poetika: Jurnal Ilmu Sastra, IV(1).

Ratna, N. K. (2005). Sastra dan Cultural Studies: Representasi Fiksi dan Fakta. Pustaka Pelajar.

Ratna, N. K. (2007). Teori, Metode dan Teknik Penelitian Sastra: dari Strukturalisme hingga Postrukturalisme. Pustaka Pelajar.

Sayuti, A. T. (2019). Pemeranan Tokoh Ma'e Dalam Naskah Mega-Mega Karya Arifin C.Noor Dengan Metode Akting Stanislavsky. Creativity And Research Theatre Journal, $1(1), 1-12$.

Sumardjo, J., \& Saini. (1986). Apresiasi Kesusastraan. PT. Gramedia.

Widodo. (2020). Moral Dan Nilai Kepribadian Tokoh Utama Dalam Novel Dunia Sophie Karya Jostein Gander. Lingua Rima: Jurnal Pendidikan Bahasa Dan Sastra Indonesia, $9(2), 1$. 